\title{
Cores e pedagogias do discurso zapatista
}

Antonio Andrade ${ }^{\mathbf{a}}$ (D)

Patricia Araujo Fernandes ${ }^{\mathrm{b}, \mathrm{c}}$ (D)

\begin{abstract}
Resumo
Neste artigo, dedicamo-nos a refletir sobre a inflexão pedagógica decolonial do discurso zapatista, trazendo à discussão o papel simultaneamente político e educacional que a apropriação de um texto narrativo literário indicia nesse contexto de militância. Para tanto, analisamos o comunicado do Exército Zapatista de Libertação Nacional (EZLN) - movimento de resistência indígena mexicano - intitulado La historia de los colores (EZLN, 1994), escrito pelo Subcomandante Marcos. Para a elaboração do dispositivo teórico-analítico deste trabalho, articulamos, de maneira transdisciplinar, determinadas perspectivas dos estudos discursivos (ORLANDI, 2001; FOUCAULT, 1988), indagações advindas das ciências sociais a respeito das epistemologias do Sul (SANTOS, 2018) e debates relacionados à pedagogia decolonial (WALSH, 2013; OLIVEIRA; CANDAU, 2010).
\end{abstract}

Palavras-chave: Discurso; Pedagogia Decolonial; Literatura; Epistemologias do Sul; Movimento Zapatista.

Recebido em: 09/03/2021 Aceito em: 27/05/2021

\footnotetext{
aUniversidade Federal do Rio de Janeiro. Rio de Janeiro, RJ, Brasil. E-mail: antonioandrade.ufrj@gmail.com bSecretaria Municipal de Educação (SME-RJ). Rio de Janeiro, RJ, Brasil.

'Universidade Federal do Rio de Janeiro, Programa de Letras Neolatinas. Rio de Janeiro, RJ, Brasil.

E-mail: patriciaaraujofernandes@gmail.com
}

\section{Como citar:}

ANDRADE, A.; FERNANDES, P.A. Cores e pedagogias do discurso zapatista. Gragoatá, Niterói, 
1 “Nossa arma é nossa palavra" (tradução nossa).
Nuestra arma es nuestra palabra. ${ }^{1}$

Subcomandante Marcos (2001)

\section{Introdução}

Este artigo apresenta uma análise do comunicado do Exército Zapatista de Libertação Nacional (EZLN), intitulado La historia de los colores (EZLN, 1994), sob a ótica de estudos discursivos, em articulação com as ciências sociais e com o campo da pedagogia decolonial. O referido comunicado, que possui características narrativas ficcionais, foi publicado originalmente em 10 de outubro em 1994 pelo Subcomandante Marcos, considerado o principal porta-voz do EZLN, movimento de resistência indígena de Chiapas no México.

Nosso objetivo principal aqui é refletir sobre os mecanismos de produção e circulação do discurso zapatista, avaliando seus procedimentos retóricos, sua diferença epistemológica, a criticidade política de seu gesto enunciativo, assim como a potencialidade performativa e educacional de seu desdobramento e de sua inflexão na esfera discursiva do literário, ligada aos processos de (re)construção das identidades culturais.

Em paralelo a isso, almejamos discutir também como a escrita do Subcomandante Marcos - escritor e intelectual que se tornou a maior referência do movimento zapatista - promove, a partir do contexto sócio-histórico mexicano, diferentes modos de agenciamento e de resistência político-cultural, deslocando as formas de posicionamento inscritas na formação discursiva da militância de esquerda na América Latina em direção a uma proposição mais atenta às epistemologias dos povos originários, às narrativas e aos saberes das comunidades indígenas, tal como se percebe em La historia de los colores, texto que constitui o corpus de análise em foco aqui.

\section{Discurso zapatista: outras epistemologias}

Partimos do pressuposto teórico de que o discurso constitui uma dupla dispersão, entrecruzando, por um lado, 
vários dizeres que circulam num dado tempo/espaço, e intersectando, por outro, várias posições que o sujeito pode ocupar. Todo discurso é ideológico, logo, o sujeito é também ideologicamente marcado, e sua relação com a linguagem está ligada à sua relação com o mundo, em termos históricos, sociais, culturais e políticos.

Desse modo, entendemos que a linguagem apresenta uma relação com a exterioridade e se estabelece no bojo de relações de força e de saber-poder em disputa na dinâmica da vida social. Nesse sentido, aderimos à perspectiva dos estudos discursivos, segundo a qual tomar a palavra implica uma forma de ação e de transformação, um ato simbólico e performativo: "tomar a palavra é um ato social com todas as suas implicações, conflitos, reconhecimentos, relações de poder, constituição de identidade, etc." (ORLANDI, 2001, p. 17).

Na esteira de tal concepção teórica, almejamos propor uma reflexão em torno do modo como a discursividade que atravessa as práticas do EZLN, buscando promover agenciamentos e transformações de ordem política e educacional num dado contexto histórico nacional latino-americano, cria ancoragens não apenas em gêneros e documentos originariamente provenientes da esfera didático-pedagógica stricto sensu, mas também no discurso literário, esfera na qual a produção textual, de acordo com Maingueneau (2006, p. 44), engendra "a própria gestão de seu contexto", de tal modo que as "obras [literárias] falam de fato do mundo, mas sua enunciação é parte integrante do mundo que se julga que elas representem".

Tal funcionamento do discurso que se observa, talvez mais nitidamente, em textualidades apropriadas pelas práticas de militância indicia o modo instigante como, dentro do campo literário, vêm sendo performatizadas estratégias de intervenção nas políticas linguístico-culturais, mostrando assim uma coparticipação da literatura no processo de visibilização das "epistemologias do Sul", as quais segundo Boaventura de Sousa Santos "se referem à produção e validação dos conhecimentos ancorados nas experiências de resistência de todos os grupos sociais que sistematicamente têm sofrido a injustiça, a opressão e a destruição causada pelo capitalismo, o colonialismo e o patriarcado" (SANTOS, 2018, p. 300).

Nesse sentido, é fundamental reconhecermos o valor crítico contra-hegemônico do processo de transposição e 
tradução intercultural, empreendido pelo Subcomandante Marcos, dos mitos e histórias orais - originados nas línguas indígenas dos grupos étnicos Choles, Mames, Tseltales, Tojolabales, Tsotsiles e Zoques - para o universo discursivo de um gênero narrativo literário, vinculado à tradição letrada e escrito em língua espanhola. Esse gesto enunciativo inverte, por um lado, o movimento de filiação da história literária canônica aos valores eurocêntricos, corresponsável pelo silenciamento dos saberes ameríndios na formação da memória nacional. Por outro lado, desconstrói fronteiras epistêmicas entre o que é legítimo ou não de constituir os processos de letramentos, no âmbito da educação linguística, funcionando assim como uma estratégia pedagógica de caráter decolonial (WALSH, 2013).

Em outras palavras, queremos frisar que o discurso zapatista traz à baila formas de diálogo das práticas de guerrilha, militância e resistência política com os saberes culturais minorizados. Desse modo, visa a resistir à lógica opressiva de colonização do imaginário engendrada tanto pelo Norte - isto é, pelos grupos dominantes na ordem mundial do capitalismo - quanto pelo Sul imperial (Santos, 2018, p. 126), ligado às oligarquias que se estabeleceram no Sul Global, fazendo avançar processos de destruição das línguas e dos conhecimentos locais, em prol da hegemonia de uma episteme vinculada à modernidade capitalista.

\section{Ideologia, poder, resistência}

Em toda sociedade existem procedimentos de exclusão e de silenciamento do dizer. Pensar o discurso zapatista, a partir da ótica do apagamento contra o qual ele resiste, permite-nos vislumbrar paradigmas de submissão cristalizados no contexto sociocultural latino-americano. Os mecanismos de controle do discurso são assim atravessados pelo ideológico e fazem com que a alteridade passe por formas de interdição oriundas das relações de poder que estratificam a tessitura social.

De acordo com Louis Althusser (1970, p. 86), “A ideologia representa a relação imaginária dos indivíduos com suas condições reais de existência". Nesse sentido, a ideologia é entendida como algo vivido na experiência do cotidiano, materializando-se em práticas discursivas e não discursivas naturalizadas. Althusser desenvolve em seus escritos a noção 
${ }^{2}$ Orlandi (2002, p.

27) destaca que

com a posição de

Althusser - filósofo

de extração marxista

que influenciou,

sobremaneira, os estudos discursivos

- "a linguagem não aparece mais como simples acessório do político, nem da ciência", a partir dele é importante atentar para a problemática constitutiva do discurso teóricoacadêmico, visto que

"o sujeito de ciência que pratica a análise de discurso se expõe à [...] posição sujeito político que seu investimento teórico anuncia".

\footnotetext{
3 "Aqui o povo manda e o governo obedece" (tradução nossa).

4 “[...] supõe um esforço para reorganizar as bases [...] Isso implica duas coisas: 1) a disposição de realizar uma estratégia política interna para construir e coordenar o zapatismo regional sob uma autoridade civil comum supracomunitária, a fim de manter a 'resistência' de forma mais disciplinada; $\mathrm{e}$ 2) a redefinição das relações do zapatismo com as comunidades, as organizações camponesas e políticas e o governo do Estado" (tradução nossa).
}

de Aparelhos Ideológicos de Estado (AIE), os quais funcionam não apenas pela imposição da força, mas por uma confluência entre os dispositivos ideológicos e repressivos. Para o teórico, "uma ideologia existe sempre num aparelho" (ALTHUSSER, 1970, p. 77). Se a classe dominante detém o poder do Estado, consequentemente detém o aparelho (repressivo) de Estado e age/interfere sobre os diferentes AIE (religião, escola, imprensa, instituições culturais etc.). Porém, os AIE não são apenas instrumentos da classe dominante, mas sobretudo palco de uma árdua e ininterrupta luta de classes ${ }^{2}$.

Foucault (1988), no entanto, desloca a ideia de "aparelhos ideológicos", questionando nela a existência de uma lógica biunívoca entre poder e Estado. Desse modo, o poder na visão foucaultiana é visto como uma potência dispersiva, que se manifesta numa articulação entre poderes locais, específicos, institucionais etc. Seguindo tal concepção, Foucault afirma que o poder não é algo apenas coercitivo, mas também produtivo, visto que intervém materialmente nos processos de subjetivação, na linguagem e no desenvolvimento dos saberes, atravessando corpos e mentes.

É importante apontar que o EZLN - pautado numa visão marxista que, poderíamos dizer, dialoga com a noção althusseriana de AIE - investe num processo de reestruturação das formas de organização do político e de redistribuição institucional do poder no contexto das comunidades chiapanecas. Não à toa, um dos slogans zapatistas mais conhecidos é o enunciado "Aquí manda el pueblo y el gobierno obedece" . De acordo com Estrada Saavedra, o movimento zapatista:

[...] supone un esfuerzo por reorganizar las bases [...] Esto implica dos cosas: 1) la voluntad de llevar a cabo una estrategia política interna para cohesionar y coordinar al zapatismo regional bajo una autoridad civil común supracomunitaria en vista a mantener la "resistencia" de una manera más disciplinada; y 2) la redefinición de las relaciones del zapatismo con comunidades, organizaciones campesinas y políticas y el gobierno del Estado. ${ }^{4}$ (ESTRADA SAAVEDRA, 2006, p. 54)

Mas se o Estado não é a única instância detentora do poder, espraiando-se e desdobrando-se de maneiras múltiplas 
e descontínuas, podemos dizer que o pensamento foucaultiano constitui dois importantes problemas para a visada marxistaalthusseriana. O primeiro é que, se o poder não tem centro, sua tomada pela classe dominada e a modificação dos AIE não são suficientes para fazer desaparecer ou transformar as redes de poderes que subsistem na sociedade. $\mathrm{O}$ outro relacionase à ideia de uma microfísica do poder, que faz com que o fundamento marxista da luta de classes tenha sua centralidade questionada. Desse modo, entendemos que as lutas contra o exercício do poder não são externas ao poder, por não estarem isentas dele. O poder é uma construção ideológica que interpela o sujeito historicamente constituído.

Marx e Foucault divergem no que tange à conceituação de ideologia e poder. No marxismo, o poder, vinculado tanto ao nível da infraestrutura quanto ao da superestrutura, é resultado de estratégias dos grupos dominantes, que detêm o controle dos AIE para a consolidação e perpetuação de sua hegemonia e com o objetivo de manter seus interesses e relações econômicas. Já para Foucault, o Estado não é, necessariamente, o ponto de partida para a origem do poder, uma vez que os poderes estão disseminados de maneira multiforme: "o poder está em toda parte; não porque englobe tudo, e sim porque provém de todos os lugares" (FOUCAULT, 1988, p. 89).

Ainda que opostos pelas disputas teórico-acadêmicas na área de humanidades, é importante hoje pensarmos caminhos de correlação entre a concepção crítica marxista em relação às estruturas geradas pela luta de classes e a visão foucaultiana a respeito dos mecanismos de disseminação do poder que incidem sobre os processos de subjetivação. $\mathrm{Ou}$ seja, precisamos construir um entre-lugar teórico de reflexão a respeito de estratégias anfíbias de resistência que se produzam nos níveis macro e micro, apropriando-nos dos saberes que estão à margem, sem ignorar seus diálogos tensivos com os saberes do centro, a fim de construirmos coletivamente novas possibilidades de refundação da hegemonia.

Tal aproximação justifica-se ainda na medida em que percebemos nas propostas defendidas pelos enunciados do EZLN uma espécie de hibridização entre visões de mundo diferentes: a marxista-leninista (relacionada à formação discursiva militante) e a maia. Note-se, a título de mobilização deste debate apenas - visto que aprofundaremos mais à 
frente a discussão sobre tais processos de hibridização entre discursividades e visões de mundo -, a seguinte afirmação do Subcomandante Marcos:

\begin{abstract}
Nós chegamos à selva como uma clássica elite revolucionária em busca desse sujeito, o proletariado, no caso da revolução marxista-leninista. Mas essa proposta inicial entrou em choque com as propostas das comunidades indígenas, que têm outro substrato, uma complexa pré-história de emergências e insubmissões. Nós modificamos nossa proposta interativamente. O EZLN não nasce de propostas urbanas, mas tampouco de propostas vindas exclusivamente das comunidades indígenas. Nasce dessa mescla, desse coquetel molotov, desse choque que produz um novo discurso. $\mathrm{O}$ que dissemos é que a transformação histórica não deve ser feita à custa da exclusão de setores da sociedade. (SUB. MARCOS apud ARELLANO; OLIVEIRA, 2002, p. 42)
\end{abstract}

${ }^{5} \mathrm{Em} 1^{\mathrm{o}}$ de janeiro de 1994, o Exército Zapatista de Libertação Nacional emerge publicamente, declarando guerra ao governo do México. O levante armado zapatista ocorreu no estado mexicano de Chiapas, durou 12 dias e alcançou repercussão internacional.
A civilização maia passou por processo de declínio desde muito antes da invasão dos espanhóis em 1492 e, com isso, os herdeiros da cultura milenar maia foram construindo historicamente formas de resistência às condições de exploração e submissão. Sendo assim, no levante do EZLN de $1^{\circ}$ de janeiro de $1994^{5}$, seu gesto de reatualização da resistência reverbera um posicionamento discursivo aguerridamente contrário ao projeto neoliberal a que aderem as classes dominantes no México, e na América Latina de maneira geral, reelaborando bandeiras de luta da esquerda, a partir do seu universo cultural e de suas formações imaginárias.

Pensando outro paralelo possível da concepção foucaultiana - que imbrica as noções de poder, discurso e subjetivação - com o pensamento marxista, pode-se dizer, com Marx (2003, p. 7), que “Os homens fazem sua própria história, mas não a fazem como querem; não a fazem sob circunstâncias de sua escolha, e sim sob aquelas com que se defrontam diretamente, legadas e transmitidas pelo passado". O sujeito é, portanto, permeado de valores de natureza cultural externos a ele ao longo da vida e, consequentemente, formado por tais valores, os acaba interiorizando e, assim, formando a sua compreensão do poder. Observa-se, nesse sentido, que diversos vetores que atravessam o sujeito (narrativas, crenças, processos de escolarização, mídias etc.) são corresponsáveis pela sua formação ideológica, o que gera a reprodução, ainda 
que sempre deslocada/reterritorializada, deste processo formativo.

Porém, é importante reconhecermos que os lugares de legitimidade e de escuta são variáveis e dependem, em grande parte, da importância social que o sujeito carrega, de acordo com os valores identitários que lhe são atribuídos historicamente. Assim, é possível verificar que, em diversas sociedades marcadamente machistas e patriarcais, o peso de fala de uma mulher tende a ser menor que a de um homem. Do mesmo modo, em muitas sociedades que classificam o poder também de acordo com uma lógica étnico-racial, a fala de um não branco é menor que a de um branco. Dessa forma, é importante atentarmos também, na análise do discurso zapatista, vinculado ao contexto histórico e político latino-americano, para a interseccionalidade entre gênero, raça e classe na hierarquização dessas vozes na dinâmica sociodiscursiva.

\section{Interface literatura/pedagogia decolonial}

Este trabalho pauta-se também no campo da pedagogia decolonial. Por isso, posiciona-se no escopo de uma perspectiva crítica com relação ao discurso, à ideologia e aos processos de disciplinarização dos corpos e subjetividades, adotando uma abordagem de discussão política em relação ao saber.

Em conformidade ao direcionamento crítico dessa reflexão, cabe assinalar que o processo de legitimação de saberes no âmbito da cultura letrada ocidental teve como base a matriz epistemológica moderna eurocêntrica. No percurso histórico de formação desse paradigma epistemológico, subsistem vários mecanismos que interligam discursivamente saber e poder. Para Oliveira e Candau (2010, p. 21):

a colonialidade do poder criou uma espécie de fetichismo epistêmico (ou seja, a cultura, as ideias e os conhecimentos dos colonialistas aparecem de forma sedutora que se busca imitar), impondo a colonialidade do saber sobre os nãoeuropeus [...], o poder, o saber e todas as dimensões da cultura definiam-se a partir de uma lógica de pensamento prefigurada pela Europa.

O monopólio e a hegemonia do poder/saber têm uma de suas expressões no padrão de funcionamento da escola 
moderna, o qual vem se mantendo, ao longo do tempo, a serviço do sistema dominante. Esse processo tem como modelo educacional teorias, categorias e conceitos reduzidos ao pensamento euro-americano: "a colonialidade é constitutiva da modernidade e não derivada" (Mignolo, 2005, p. 75).

Os cânones literários nacionais, bem como os cânones escolares de ensino de literatura, filiados ao pensamento hegemônico moderno, também vêm ocultando historicamente saberes (e diferentes formas de produção de saberes), promovendo silenciamentos.

O modelo de educação de caráter colonial se caracteriza por ser dominante e dominador, uma vez que não reconhece outros saberes, nega a alteridade e a pluralidade, apagando memórias e histórias que constituem os sujeitos. Esse processo foi e vem sendo construído por imposição e legitimação de determinadas elites, por meio de estratégias de segregação e minimização de outros sujeitos. Contudo, é preciso reconhecer a agência de educadores não conformados a esse modelo e os movimentos contra-hegemônicos que vêm se desenvolvendo há várias décadas, inclusive, a partir de vozes importantes do pensamento pedagógico brasileiro, a exemplo da reflexão seminal de Paulo Freire em torno das formas de opressão das classes populares implicadas na tradição educacional transmissiva e afastada do universo cultural dos sujeitos da escola pública (FREIRE, 1987).

$\mathrm{Na}$ atualidade, o debate a respeito da proposição de uma pedagogia decolonial faz essa visada crítica avançar em busca da desconstrução desse modelo colonial de ensino/ aprendizagem, lançando luz sobre propostas e práxis educativas que visem como tarefa permanente à elaboração de projetos integrados, capazes de dialogar e reconhecer a inclusão de diversos sujeitos e saberes, subvertendo assim a hegemonia discursiva da estrutura de poder. De acordo com Catherine Walsh:

Nos referimos a una praxis pedagógica crítica, intercultural y de-colonial que pretende pensar no sólo "desde" las luchas de los pueblos históricamente subalternizados, sino también "con" sujetos, conocimientos y modos distintos de estar, ser y vivir, dando un giro a la uninacionalidad y monoculturalidad fundantes de la empresa educativa y su razón moderno-occidental-capitalista, para dar centralidad, 
6 "Referimos-nos a uma práxis pedagógica crítica, intercultural e decolonial que visa pensar não apenas 'a partir' das lutas dos povos historicamente subalternizados, mas também 'com' sujeitos, conhecimentos e diferentes formas de estar, ser e viver, invertendo assim a uninacionalidade e a monoculturalidade fundantes da empresa educativa e sua razão moderna-ocidentalcapitalista, para dar centralidade à vida $\mathrm{e}$, portanto, ao trabalho ainda incompleto de humanização e descolonização" (tradução nossa).

\footnotetext{
7 "Processo accional, tipicamente realizado de maneira coletiva e não individual, [que] suscita reflexões e ensinamentos sobre a própria situação/ condição colonial e o projeto inacabado de descolonização, ao mesmo tempo que gera atenção às práticas políticas, epistêmicas, vivenciais e existenciais que lutam para transformar os padrões de poder e os princípios sobre os quais o conhecimento, a humanidade e a própria existência foram circunscritos, controlados e subjugados" (tradução nossa).
}

8“Desde a ótica
decolonial, as práticas
políticas educacionais
que continuam a
ser construídas
nas comunidades
autônomas zapatistas
são a expressão de
uma redefinição dos
papéis atribuídos aos
atores individuais e
coletivos. Estas geram
a invenção social de
práticas alternativas
de organização dos
serviços educativos
locais, de acordo
com os direitos

8 "Desde a ótica decolonial, as práticas que continuam a são a expressão de uma redefinição dos papeis atribuídos aos coletivos. a invenção social de práticas alternativas serviços educativos com os direitos más bien, a la vida y, por ende, al trabajo aún incompleto de la humanización y descolonización. ${ }^{6}$ (WALSH, 2009, p. 16)

Desse modo, a proposta de educação pautada numa visão decolonial pretende estabelecer uma postura crítica e de resistência, em oposição, ao mesmo tempo, a um sistema educacional e a uma política cultural de bases colonialistas. Para Walsh, o conceito de pedagogia decolonial pode ser entendido como:

\begin{abstract}
Proceso accional, típicamente llevado de manera colectiva y no individual, [que] suscita reflexiones y enseñanzas sobre la situación/condición colonial misma y el proyecto inacabado de la des- o de- colonización, a la vez que engendran atención a las prácticas políticas, epistémicas, vivenciales y existenciales que luchan por transformar los padrones de poder y los principios sobre los cuales el conocimiento, la humanidad y la existencia misma han sido circunscritos, controlados y subyugados. ${ }^{7}$ (Walsh, 2013, p. 29)
\end{abstract}

Uma perspectiva decolonial implica assim reivindicar mudanças de práticas e posicionamentos historicamente construídos, responsáveis pelo silenciamento de saberes, sujeitos, histórias, tradições e memórias locais. Nesse sentido, as comunidades zapatistas, aproximando-se a um olhar decolonial, organizam uma redefinição de suas práticas pedagógicas. De acordo com Bruno Baronnet:

Desde una óptica decolonial, las prácticas de política educativa que se siguen construyendo en las comunidades autónomas zapatistas son la expresión de una redefinición de los roles atribuidos a los actores individuales y colectivos. Éstas generan la invención social de prácticas alternativas de organización de los servicios educativos locales, de acuerdo con los derechos políticos, las identidades y las estrategias de los pueblos originarios. ${ }^{8}$ (BARONNET, 2013, p. 307)

A partir dessa ótica decolonial, é possível pensarmos que a educação zapatista busca estratégias identitárias coletivas que acionam diferentes esferas discursivas, como a da literatura, de modo a romper com o processo de replicação escolar dos cânones legitimados pelo sistema literário nacional, garantindo assim uma autonomia educativa em diálogo com o contexto sociocultural em que os sujeitos pertencentes a essas comunidades estão inseridos: "Se trata de un modo alternativo de 
políticos, identidades e estratégias dos povos originários" (tradução nossa).

\section{${ }^{9}$ "Se trata de um modo alternativo de integração a 'um mundo onde caibam muitos mundos', de acordo com a famosa fórmula do EZLN" (tradução nossa).}

${ }^{10}$ “Em 17 de novembro de 1983, um pequeno grupo de indígenas e mestiços chegou à Selva Lacandona. Em um acampamento da montanha, sob o abrigo e uma bandeira preta com uma estrela vermelha de cinco pontas, eles formalmente fundaram o Exército de Libertação Nacional Zapatista"' (tradução nossa). integración a 'un mundo donde quepan todos los mundos' según la famosa fórmula del EZLN"9 (BARONNET, 2013, p. 327).

\section{Contextualização histórico-cultural do EZLN}

Apesar do impacto ocorrido no levante de 1994, o movimento zapatista vem de um processo histórico de articulação muito anterior a essa data. De acordo com Muñoz Ramírez:

El 17 de noviembre de 1983 un reducido grupo de indígenas y mestizos llegó a la Selva Lacandona. En un campamento de montaña, bajo el cobijo y una bandera negra con estrella roja de cinco puntas, fundaron formalmente el Ejército Zapatista de Liberación Nacional. ${ }^{10}$ (MUÑOZ RAMÍREZ, 2003, p. 27)

Dez anos depois, o movimento se insurge contra o governo do México, recuperando a memória política da Revolução Mexicana de 1910 e da figura de Emiliano Zapata. Diferentes estudos fazem um histórico do movimento zapatista mexicano. Tomamos de empréstimo a seguinte citação de Pedro Henrique Falco Ortiz, que apresenta o ocorrido no levante do EZLN:

PRIMEIRO de janeiro de 1994. Em muitos lares mexicanos os champanhes estouraram comemorando a chegada do ano novo e a entrada em vigor do Nafta (North American Free Trade Agreement) ou TLC (Tratado de Livre Comércio), o acordo comercial entre Estados Unidos, Canadá e México, a tão anunciada porta para o chamado primeiro mundo, como não cansou de propagandear o governo do então presidente mexicano Carlos Salinas de Gortari, eleito em 1988, em pleito que teve o resultado contestado pela oposição ao PRI (Partido Revolucionário Institucional). Mas naquela mesma madrugada de festa, das entranhas do esquecido México, no coração da longínqua Selva Lacandona, milhares de mestiços e índios das etnias tsotsil, tseltal, tojolabal, chol, mame e zoque, herdeiros da cultura maia, desceram das montanhas para ocupar várias cidades e localidades do empobrecido Estado de Chiapas, no sul do país, região fronteiriça com a Guatemala. Surgiram das brumas da noite como guerrilheiros do autodenominado e até então desconhecido Exército Zapatista de Libertação Nacional - EZLN, surpreendendo em suas ações-relâmpago não só à sociedade e ao governo mexicano, mas a todo o mundo. (ORTIZ, 1997, p.16) 
Historicamente o México viveu tensões étnicas de diferentes intensidades. A possibilidade de uma ameaça de conflito entre o EZLN e o Estado mexicano colocou a população indígena no centro das discussões do país. Desde $1^{\circ}$ de janeiro de 1994, o tema indígena passou a fazer parte das agendas de partidos políticos, meios de comunicação, instituições responsáveis pela defesa e segurança nacional.

Nesse sentido, se as manifestações culturais possuem sempre um caráter político, seja aderindo ao imaginário e aos valores hegemônicos, seja resistindo a eles, o EZLN pode ser visto como um movimento de resistência contra-hegemônica, tanto de natureza política quanto cultural. Sendo assim, este movimento não só reproduz, mas também produz cultura. Mignolo (1997) considera, dessa maneira, que o zapatismo realiza uma revolução cultural, tanto em sua forma de agir quanto de enunciar, entendendo-o como uma espécie de revolução teórica, encetada não só pelo campo acadêmico, mas por distintas esferas da sociedade. $\mathrm{O}$ autor vai dizer o seguinte:

\begin{abstract}
El zapatismo es un momento fundamental de esta revolución cultural, como revolución teórica en verdad, como momento de un vuelco gnoseológico, más allá de la hermenéutica y de la epistemología. Es decir, como negación de la posibilidad de ser representado por las ciencias sociales. Esto es, sí puede ser representado, pero ya su misma existencia cuestiona las tranquilas aguas del sujeto de las ciencias "representando" el fenómeno social. El zapatismo es su "propia representación" como enacción; es decir, como vuelco hacia una gnoseología de la enacción más que una epistemología de la representación. ${ }^{11}$ (MIGNOLO, 1997, p. 65)
\end{abstract}

11"O zapatismo é um dessa revolução cultural, como uma revolução teórica na verdade, como um momento de uma virada gnoseológica, além da hermenêutica e da epistemologia. Ou seja, como negação da possibilidade de ser representado pelas ciências sociais. Isto é, pode ser sim representado, mas sua própria existência já funciona como um questionamento das águas calmas do assunto das ciências, que se destinam a 'representar' o fenômeno social. $\mathrm{O}$ zapatismo é a sua 'própria representação' enquanto performance; ou seja, como uma virada em direção a uma gnoseologia da performance, mais do que uma epistemologia de representação" (tradução nossa).
Desse modo, o zapatismo enquanto fenômeno cultural performatiza outras discursividades, outras poéticas e outras estéticas em geral, de modo a construir espaços alternativos de identificação simbólica e imaginária, uma vez que não se vê representado pelas práticas culturais hegemônicas, que partem de um funcionamento da memória ligado ao processo colonizador.

Tal concepção, que desde a década de 1980, como vimos, vem se unificando em torno de um projeto de resgate e valorização dos povos ameríndios no México, reconceitua as culturas indígenas "a partir do espaço político e teórico do popular, isto é, como culturas subalternas, porém possuidoras 
de uma existência positiva, capaz de desenvolvimento" (MARTÍN-BARBERO, 2003, p. 273), colocando em circulação efeitos de sentido potencialmente críticos e polissêmicos.

\section{As cores da história: lição indígena de diversidade}

No comunicado La historia de los colores, escrito pelo Subcomandante Marcos, encena-se - através da mescla entre estruturas composicionais do conto literário, da narrativa folclórica e da literatura infantil - o encontro entre o líder zapatista e o Viejo Antonio, ancião da região de Chiapas que conta como os deuses criaram as cores, utilizando metáforas e simbologias que dialogam, simultaneamente, com importantes elementos da memória ameríndia e com o debate em torno da questão decolonial.

Desse modo, o texto recupera uma lenda indígena de Chiapas, transpondo-a da oralidade para a construção escrita. A partir do registro e da "criação por escrito dos contos [...] o narrador assumiu esta função de contador-criador-escritor de contos, afirmando, então, seu caráter literário" (GOTLIB, 1995 , p. 5). Entendemos que as tradições orais constituem a dinâmica da cultura popular, porém cabe ressaltar que essa reconstrução e reafirmação escrita das tradições indígenas também configuram um gesto de resistência e (re)existência.

O texto trata da importância e da constatação da diversidade, projetando por meio do ficcional um espaço/ tempo narrativo onde sujeitos, discursos e forças heterogêneas possam coexistir. Essa produção de caráter estético-literário funciona como prática social, relacionada às estruturas que a produzem, exercendo um papel fundamental na construção, transformação e/ou manutenção de representações, (re) elaboradas cotidianamente.

O comunicado La historia de los colores (EZLN, 1994), divulgado em 27 de outubro de 1994, faz parte da fase inicial do Movimento Zapatista, de 1993-1996, caracterizada como fase de formação. Tem como destinatários veículos da imprensa mexicana, tais como os jornais Proceso, La Jornada, El Financiero, Tiempo, além do público em geral.

Nele, o Subcomandante Marcos conta o que lhe aconteceu ao chamar a atenção de um menino sobre o que este fazia com umas formigas, bem como a consequência desse ato, qual 
${ }^{12}$ "'Por acaso, pegamos em armas pelas formigas', diz Ana Maria. Eu acendo o cachimbo e digo, olhando o pequeno jogo de chá abandonado pelo chapeleiro louco e a lebre de março: 'Não para elas, mas também par elas."' (tradução nossa).

${ }^{13}$ "Não por elas, mas também por elas" (tradução nossa).
${ }^{14 "}$ Eu me viro e me sento ao lado dele. 'Você acha que nós vamos chegar ao povoado antes que chova?', pergunto-lhe enquanto acendo o cachimbo. O velho Antonio parece não escutar. Agora é uma revoada de tucanos o que distrai a sua vista. Em sua mão, o charuto espera o fogo para iniciar o lento desenho da fumaça" (tradução nossa). seja: uma discussão com Ana María, uma das mulheres do movimento, que o adverte em relação à "bronca" que deu no menino. Vejamos a primeira sequência discursiva (doravante $\mathrm{SD})$ referente ao texto analisado:

SD 1: "Acaso nos alzamos en armas por las hormigas", dice, en jarras, Ana María. Yo enciendo la pipa y digo, mirando el pequeño juego de té abandonado por el sombrerero loco y la liebre de marzo: "No por ellas, pero también por ellas". ${ }^{12}$ (EZLN, 1994, s/p - grifos nossos)

Ana María indaga se a luta que estão travando seria para defender as formigas e, em sua resposta, Marcos, em meio à intertextualidade com a obra de Lewis Carroll (Alice no País das Maravilhas), já anuncia uma das máximas do EZLN: "No por ellas, pero también por ellas"13. O enunciado em destaque se inscreve na história em que as personagens estão inseridas. $\mathrm{O}$ discurso, enquanto lugar de disputa e de mediação políticoideológica, tenta transformar a realidade social, produzindo e compartilhando o efeito de sentido de que a luta é pela vida de todo ser vivo. Os enunciados, na configuração dessa narrativa, se articulam em prol da construção de uma consciência coletiva, isto é, de uma conscientização social em relação aos processos de assujeitamento à ordem do discurso hegemônico e à exploração dessas comunidades pelas classes dominantes. E, não à toa, esse é o ensejo para a história narrada por Marcos às crianças, que, já apaziguados os ânimos, se aproximam solicitando o relato.

Marcos, depois de seu ritual de acender o cachimbo, afirma que a história será contada tal como a contou o Viejo Antonio, figura que, mesmo em meio à luta em plena selva, cria e recria a cultura dos povos originários, narrando histórias que alimentam o imaginário e a forma de ver o mundo indígena mexicano. Isso pode ser observado na sequência discursiva abaixo:

SD 2: Me vuelvo y me siento a su lado. "¿Usted cree que llegaremos al pueblo antes de que llueva?", le pregunto mientras enciendo la pipa. El viejo Antonio parece no escuchar. Ahora es una parvada de tucanes lo que distrae su vista. En su mano el cigarro espera el fuego para iniciar el lento dibujo del humo. ${ }^{14}$ (EZLN, 1994, s/p - grifos nossos) 
No movimento de narrar o que já lhe foi contado, Marcos cria um círculo que recupera a figura do "narrador", aquele capaz de apresentar o mundo. O Subcomandante, com vistas a atualizar a cultura indígena, ressignifica o poder da experiência, da tradição e da memória, tal qual o narrador descrito por Benjamin (1987, p. 198), para quem "A experiência que passa de pessoa a pessoa é a fonte a que recorrem todos os narradores", colocando assim a arte de contar no espaço das narrativas orais e fundacionais. Segundo o filósofo, existem dois tipos fundamentais de narradores: o sujeito que viaja e, por isso, tem muito a contar sobre o que viu e experienciou, $\mathrm{e}$ o que tem muito a dizer porque, já em idade avançada, guarda consigo as histórias e tradições de sua comunidade. Esses dois tipos se interpenetram e, ao longo do tempo, vão delineando a figura dos "homens do narrar".

O narrador-personagem que é encenado no texto através da figura do Subcomandante Marcos pertence à linhagem dos agentes, que, a partir de uma memória discursiva, ativam conhecimentos e perspectivas das culturas chiapanecas, corroborando aí um processo discursivo de afirmação cultural ao enunciá-los. Ao (re)criar no âmbito da construção narrativa o personagem do Viejo Antonio, o enunciador traz para o primeiro plano as narrativas formadoras e a história dos povos indígenas mexicanos. Dessa maneira, estabelece uma forma de legitimar tradições culturais tão recalcadas ao longo dos anos pela cultura mexicana oficial. Sendo assim, o que interessa na figura representativa do Viejo Antonio é sua capacidade de recuperação, transmissão e construção de saberes. Configurase, desse modo, uma forma de conexão cultural com todos

${ }^{15} \mathrm{O}$ Subcomandante Marcos também é conhecido como "el Sup". Ressaltamos aos leitores deste artigo a existência de hipóteses de que o Sub. Marcos não seja apenas uma pessoa, e sim um personagem que pode ter sido assumido por diferentes membros do movimento zapatista. No entanto, entendemos que não cabe no escopo deste trabalho questionar a autoria dessa figura reconhecida pelo EZLN como seu portavoz. os que participam do EZLN, ou que dialogam com ele, para explicar o que reivindica o movimento. A formação dos que participam da luta, bem como das gerações futuras, passa pelo conhecimento do que são e onde desejam chegar. E a instância do narrador, identificada nesse texto à figura do "Sup"15, cumpre um importante papel educativo nesse sentido. São histórias que apresentam, em uma linguagem próxima à tradição indígena, mitos e modos de explicação da realidade que os envolve, bem como do mundo, tal qual o conhecemos hoje.

São as futuras gerações, encenadas nesse comunicado pelas crianças Heriberto e Eva, que ouvem e que serão capazes 
${ }^{16}{ }^{\prime \prime}$ Heriberto não espera a resposta e senta-se ao lado da Eva e mostra seu desenho e diz a ela que, sem tanto foguete, seu pato voa melhor que o avião do Sup. Nisso, eu já estou com meu uniforme cheio de doce, contudo, acendo o cachimbo e, depois das três tragadas de costume, começo a lhes contar a história, tal como a contou o velho Antonio" (tradução nossa). de preservar o narrado, auxiliando a construir, através de suas narrativas, uma identidade dos povos indígenas, por meio da memória e da participação efetiva na construção de uma sociedade com representatividade igualitária. As histórias "recuperadas" através da voz do Viejo Antonio formam e educam, não só a população de Chiapas, mas também a todos que são capazes de reconhecer sabedoria na alteridade, abrindo portas para que se reconheça a visão indígena como uma das perspectivas que coabitam os territórios (trans)nacionais e que compõem a vasta diversidade humana e cultural.

Como já foi assinalado, o comunicado La historia de los colores parte de uma lenda indígena muito peculiar sobre a relação das pessoas com o mundo e com as cores, levando à reflexão sobre a multiplicidade não apenas cromática, mas também das experiências e concepções de mundo. Ao iniciar a história da mesma forma que o faz Viejo Antonio, Marcos reabre o ciclo da tradição. Sentado ao lado das crianças, assim como estava ele ao lado de Antonio, acende seu cachimbo, como o Viejo acendeu seu charuto, e se distancia do tempo presente para construir uma ponte com o passado, chegando ao tempo mítico, ao tempo da criação das cores. Vejamos a sequência a seguir:

SD 3: El Heriberto no espera la respuesta y se sienta al lado de la Eva y le muestra su dibujo y le dice que, sin tanto rocket, su pato vuela mejor que el avión del Sup. Yo traigo ya medio uniforme lleno de dulce y, no obstante, enciendo la pipa $\mathrm{y}$, después de las tres bocanadas de rigor, empiezo a contarles, tal y como la platicó el viejo Antonio. ${ }^{16}$ (EZLN, 1994, n.p. - grifos nossos)

Nessa terceira SD, podemos observar que o tempo se distende, se expande, procurando o tempo fundacional. É o tempo em que tudo se suspende para inaugurar o tempo da narrativa. É hora de parar, sentar e ouvir, de acompanhar a história e fazê-la parte da vida de cada indivíduo. É o tempo de conhecer e aprender. Essa mudança de regimes temporais no plano da enunciação pode ser identificada aí por meio da ênfase inicial dada à agitação infantil, e sobretudo a do personagem Heriberto, que fala - às vezes inclusive sobrepondo-se ao turno do outro -, movimenta-se de um lado a outro e brinca, ao mesmo tempo. O narrador-personagem dá indícios também de 
sua relação de intimidade e de sua proximidade com as crianças no âmbito da cena narrada, ao dizer que já estava como o uniforme sujo de doces. Em seguida, a interposição abrupta do conector adversativo "sin embargo" estabelece um rompimento com esse comportamento um tanto ou quanto acelerado das personagens que caracteriza esse nível de introdução da narrativa, o qual parece retratar o presente das comunidades que integram o movimento zapatista. Tal mudança de estatuto temporal é reforçada simbolicamente pela pausa realizada pelo narrador-personagem ao dar três tragadas no cachimbo, antes de começar a contar às crianças a história das cores, que pela sua proximidade ao gênero lenda prescinde da configuração de um recorte temporal com o desenrolar de vicissitudes e ações de uma trama com características semelhantes à de determinado contexto histórico identificável pelo leitor. Em lugar disso, a história que o narrador (re)conta, "tal y como" ela foi contada por um ancião, é marcada pelo caráter fundacional do tempo mítico, que busca recuperar uma temporalidade originária, que não se situa cronologicamente no nível do presente enquanto atualidade, trazendo à tona saberes ancestrais e modos de explicação ameríndios para distintos aspectos relacionados à natureza e à cultura.

A narrativa começa quando o Viejo Antonio observa umas "guacamayas" (araras) e diz que, no princípio, elas eram todas quase sem cor, eram cinza como a maioria dos pássaros. Como os deuses estavam entediados porque só havia duas cores no mundo, sempre brigavam. E no dizer do velho, a briga era justa já que só havia o negro, regido pela noite, e o branco, regido pelo dia, e no meio estava o cinza, para equilibrar tardes e madrugadas e não permitir o reinado de somente duas cores. Fizeram os deuses, então, uma assembleia e resolveram criar novas cores para alegrar a vida dos homens e das mulheres.

Começaram, assim, os deuses a pensar como criariam novas cores. E foi pensando muito que o primeiro dos deuses feriu a cabeça e do sangue nasceu a cor vermelha, a terceira cor que viu o mundo. Outro buscava uma cor que representasse a esperança, depois de um longo tempo encontrou uma cor e todos resolveram, porque tudo era resolvido em assembleias, colocar o nome de verde, a quarta cor. Depois, um dos deuses resolveu escavar a terra para encontrar seu coração e, ao cavar, encontrou a quinta cor, a que deram o nome de "café" (marrom). 
${ }^{17 "}$ "todas as cores e todos os pensamentos têm seu lugar" (tradução nossa).
Outro deus se pôs a subir e tanto subiu que, ao olhar para baixo, viu a cor do mundo. Olhou tão fixamente, para poder mostrar aos demais deuses, que fixou a cor nos olhos e ficou cego. Ao descer com dificuldade, aos tropeções, mostrou a sexta cor, e eles puseram o nome de azul. O seguinte deus viu uma criança sorrindo e, ao ver a cor desse sorriso, o roubou, e os deuses colocaram o nome de amarelo para a sétima cor.

Cansados, os deuses resolveram deixar as cores em uma caixa embaixo de uma paineira e foram beber e descansar. Como a caixa não estava bem fechada, as cores saíram e se "amaram" e nasceram outras cores. A paineira, com medo de que a chuva apagasse as cores, tapou a caixa. Os deuses, quando voltaram e viram tantas cores, resolveram que subiriam na copa da paineira, já que ela havia "parido" novas cores, e dali as espalhariam. E foi o que fizeram, deixando o mundo colorido para os homens e mulheres. Depois de tanto trabalho, foram dormir. Mas antes, para não se esquecerem das cores e não as perderem, colocaram todas elas nas plumas da arara. Todas as vezes que homens e mulheres vissem uma arara se lembrariam de que, no mundo, há muitas cores e pensamentos e que "todos los colores y todos los pensamientos tienen su lugar"17 (EZLN, 1994, s/p).

Benjamin (1987) mostra em seu estudo sobre o narrador que este tem um senso prático aguçado, pois reconhece o caráter pragmático das verdadeiras narrativas. Elas têm sempre algo a ensinar, seja um ensinamento moral ou uma sugestão prática, porque o que representam está relacionado diretamente à experiência do vivido por quem narra ou às experiências dos demais observadas por ele. Desse modo, a narrativa chega aos que escutam como alegorias da vida e vão construindo camadas que se incorporam e que vão fazer parte da experiência dos ouvintes.

No entanto, quando Benjamin produz seu estudo, o faz com a finalidade de analisar também a relação entre o narrador tradicional e o narrador do romance. Há um contraponto ao longo do ensaio benjaminiano destacando as peculiaridades de cada um, mostrando, fundamentalmente, como esses dois narradores lidam com a experiência e com a relação com o outro. Segundo o autor, a forma de narrar no romance, gênero vinculado à escrita e à modernidade burguesa, se distancia profundamente da forma das primeiras narrativas. Essa 
ocorrência é fruto de uma série de fatos sociais e culturais que afetam as relações humanas e vão culminar no que ele designa como "extinção da arte de narrar" (BENJAMIN, 1987, p. 10).

Se a narrativa moderna ocidental perde o vínculo com a experiência e o contato direto entre quem conta e quem escuta, o movimento de retorno ao narrador tradicional executado ficcionalmente pelo Subcomandante Marcos parece sinalizar, a nosso ver, possíveis correspondências, melhor dizendo, um possível ponto de coincidência perdido entre práticas narrativas ainda presentes na dinâmica cultural indígena e que também demarcaram - ainda que de modos distintos e singulares - a tradição camponesa europeia anterior ao processo de expansão da imprensa e do mercado editorial. Isso aponta tanto para uma intenção autoral de trazer ao primeiro plano a cosmovisão ameríndia, quanto para um intuito (assumido coletivamente pelo EZLN) de ensinar a lidar com o conhecimento que não está em livros, por não ser registrado historicamente pela cultura letrada, mas que configura também uma cultura viva, que renasce todas as vezes em que se ouve um "cuento".

A mobilização dessa memória discursiva traz à baila concomitantemente a luta do movimento zapatista. Dessa forma, esse misto de conto, lenda e comunicado militante que é La historia de los colores recupera o ritual do contar e de ouvir, o universo da criação, o ensinamento, a oralidade, o poder da palavra, a relação com uma certa "utilidade" política da ficção - ainda que saibamos que determinados pressupostos da teoria literária moderna que advogam pela autonomia estética do construto poético-literário reneguem essa possível função discursiva da literatura -, visibilizando e/ou reconstruindo assim laços sociais e comunitários considerados pertinentes na reconfiguração dos processos de letramentos, das formas de aprendizagem e de organização coletiva.

A referência identitária do indígena como sujeito que produz história e cultura, mesmo tendo sofrido silenciamentos ao longo do processo de colonização, mobiliza memórias, narrativas e saberes que serão recontados por meio da figura do ancião. O Viejo Antonio, como a representação de um velho indígena, produz a expressão das cosmologias da região chiapaneca a partir das histórias que são contadas a Marcos. As histórias e os relatos do Viejo marcam a construção de relações identitárias existentes, as quais estão em constante processo 
${ }^{18}$ "O encontro entre o velho Antonio e Marcos é o encontro de duas cosmologias: a de intelectuais urbanos (assim se refere Marcos ao grupo de intelectuais, marxistaleninistas, que chegou da Cidade do México à selva Lacandona a princípios dos anos 1980) e se encontrou com um grupo de intelectuais indígenas [...] e comunidades indígenas" (tradução nossa). de reconstrução. Nas narrativas trazidas a público pelo EZLN, encena-se por meio da figuração autoral do Subcomandante Marcos um movimento de diálogo e apropriação do imaginário desses grupos indígenas por parte de agentes da esquerda mexicana. De acordo com Mignolo (1997, p. 63),

El encuentro entre el viejo Antonio y Marcos es el encuentro de dos cosmologías: la de los intelectuales urbanos (así se refiere Marcos al grupo de intelectuales, marxista-leninistas, que llegó de Ciudad de México a la selva Lacandona a principios de 1980) y se encontró con un grupo de intelectuales indígenas [...] y las comunidades indígenas. ${ }^{18}$

A aparição do Viejo Antonio nos escritos assinados pelo Subcomandante Marcos significa uma representação simbólica das etnias indígenas que habitam a região onde o zapatismo prosperou. A tradição da oralidade, presente na cultura indígena, se transfunde na escrita como um importante elemento discursivo. Tal transposição dos relatos orais à modalidade escrita mantém viva a história dos membros dos grupos ameríndios, revalorizando, ao mesmo tempo, as relações de pertencimento. $\mathrm{O}$ ancião enquanto personagem e voz-fonte dessa narrativa ganha aí o estatuto de mediador de conhecimentos e aspectos do mundo indígena aos leitores.

A construção literária difundida por meio da autoria da Subcomandante Marcos está atrelada ao discurso políticoeducacional zapatista. Trata-se de uma narrativa que fala não só da diversidade, mas da necessidade de convivência com a diversidade. No mundo, há tantas cores quanto pensamentos. A infinidade de tonalidades reflete-se nas incontáveis formas de ver e interagir com o que nos cerca. O EZLN projeta-se, por meio dessa postura enunciativa, como um movimento que responde aos anos de esquecimento da realidade indígena. É uma resposta, ou para usar uma noção bakhtiniana, uma atitude responsiva em relação a uma narrativa histórica oficial que não contempla a diversidade cultural. De acordo com Bakhtin (2003, p. 290),

a compreensão de uma fala viva, de um enunciado vivo é sempre acompanhada de uma atitude responsiva ativa (conquanto o grau dessa atividade seja muito variável); toda compreensão é prenhe de resposta e, de uma forma ou de outra, forçosamente a produz: [...] o ouvinte que 
${ }^{19 "} \mathrm{E}$ foi assim que a arara ficou colorida e vai por aí passeando, caso homens e mulheres se esqueçam que muitas são as cores e os pensamentos, e que o mundo será alegre se todas as cores e pensamentos tiverem seu lugar" (tradução nossa). recebe e compreende a significação de um discurso adota simultaneamente, para com esse discurso, uma atitude responsiva ativa: ele concorda ou discorda (total ou parcialmente), completa, adapta, apronta-se para executar.

Desse modo, cria-se a possibilidade de que um outro discurso seja construído, não como um bloco uniforme, mas como um espaço marcado pela heterogeneidade de diversas vozes, provenientes de outras formações discursivas e perspectivas socioculturais. O sujeito mobiliza dialogicamente todas as vozes que o antecederam, intervindo num mundo que já foi articulado e compreendido de maneiras diferentes.

Essa proposta de desconstrução de discursos homogeneizantes pode ser percebida no seguinte fragmento:

SD 4: Y así fue como la guacamaya se agarró color y ahí lo anda paseando, por si a los hombres y mujeres se les olvida que muchos son los colores y los pensamientos, y que el mundo será alegre si todos los colores y todos los pensamientos tienen su lugar. ${ }^{19}$ (EZLN, 1994, s/p - grifos nossos)

Podemos constatar aí que o dito remete ao não-dito, fazendo-se perceber como uma importante marca latente no discurso zapatista, ou seja, a questão das identidades indígenas associa-se a de inúmeras identidades, produtoras de diferentes dizeres que precisam ser respeitados e contemplados em um mundo plural (que já existe): a "guacamaya" apenas não nos deixa esquecer.

Quando presenciamos, através da voz narrativa de Marcos, o recontar de uma história popular já pertencente ao universo da oralidade, vemos que o EZLN consegue, ao mesmo tempo, deixar registro histórico dela e dar uma conotação de busca de identidade dos povos originários, apontando assim para a possibilidade de uma perspectiva e uma cosmogonia diferentes. Não à toa, Ginzburg (2006) propõe reflexão similar a esta quando trata de reconstituir superposições e cruzamentos entre a cultura popular e erudita da época da Inquisição, a partir das laudas do processo de um moleiro italiano que interpretava as ideias e os livros a que tinha acesso através de referências culturais que ele compartilhava com o mundo camponês de que também fazia parte. Dessa maneira, o testemunho desse sujeito que está num entremeio 
de discursos/culturas estabelece uma relação significativa com as tradições orais e populares, fazendo ouvir vozes silenciadas e apresentando, a partir de um registro singular, uma outra visão do mundo.

Desse modo, temos uma reconceituação da cultura em termos de discursos coletivos e visões de mundo que proporcionam o encontro de significados historicamente construídos, havendo uma interação de culturas do passado com culturas contemporâneas, formando assim um outro construto social.

Uma das importantes transformações da história, desde o período moderno até nossos dias, para a consolidação do sistema capitalista, foi a Revolução Industrial. Ali, no século XVIII, a burguesia entendeu, primeiro na Inglaterra depois no restante do mundo, que um modelo para ser hegemônico precisaria padronizar produção, religiosidade, comportamentos, estética, ética, moral.

O domínio europeu na América e na África, num primeiro momento, apresenta a força das armas, da cruz, das leis metropolitanas e do álcool, como diz, em seu Confieso que he vivido, Pablo Neruda (1974, p. 11-12). Mas feita a dominação pela força, o trabalho de ajuste fino ficaria por conta dos "aparelhos ideológicos" (ALTHUSSER, 1970): a escola, a igreja, as mídias, a família etc., os quais, embora sempre perpassados por disputas e relações de força, trataram de forjar também costumes, práticas e conceitos dominantes.

O pensamento produtivista, voltado para a obtenção do lucro, tornou-se hegemônico e vem perpassando amplamente os processos de subjetivação desde a modernidade até os tempos atuais. Porém, a esse trajeto de desdobramentos e expansão da lógica capitalista também se impuseram algumas barreiras contra-hegemônicas, e o EZLN forma uma delas. O movimento mexicano tende a deslocar a suposição de uniformidade cultural da sociedade como um todo em direção à multidirecionalidade de relações dentro de uma classe e de um estrato sociocultural.

Todorov (2009) considera que a literatura tem um papel fundamental nos processos históricos de transformação social. Uma vez que nos torna mais próximos de distintas facetas do humano, a literatura nos faz compreender melhor a complexidade do mundo. De acordo com o autor: "A nós 
${ }^{20}$ La historia de los colores foi publicada pela primeira vez em formato de livro infantil, em edição bilíngue espanholinglês, no final da década de 1990 (MARCOS, 1999). Já a edição em português brasileiro foi publicada no início dos anos 2000 (MARCOS, 2003). adultos, nos cabe transmitir às novas gerações essa herança frágil, essas palavras que ajudam a viver melhor" (TODOROV, 2009, p. 94). Desse modo, quando o EZLN busca performatizar por meio da literatura reflexões sobre o individual e o coletivo, colabora no resgate dessas "palavras" que constituem um frágil legado, sempre ameaçado pelo silenciamento. Ou seja, os discursos e saberes que atravessam essa escritura literária conformam uma espécie de herança que ajuda a (con)viver, sem apagar a diferença.

É importante ainda ressaltar que La historia de los colores foi publicada inicialmente na forma de comunicado, que se define prototipicamente como um gênero de caráter informativo, destinado em geral à publicização de declarações ou ações assumidas por determinado sujeito, grupo e/ou instituição. É possível perceber também no modo como o movimento zapatista se apropria do gênero comunicado - marcado por um registro frequentemente sintético, formal e assertivo uma clara intencionalidade de transmutação e ressignificação de seu funcionamento discursivo, explorando-o assim como uma espécie de estratégia comunicacional no âmbito da guerrilha. Note-se que não só este, mas também outros vários comunicados do EZLN configuram textualidades que se hibridizam, propositalmente, com gêneros de outros domínios do discurso. No caso específico do comunicado em foco aqui, ocorre uma imbricação com a esfera literária, a tal ponto de posteriormente o texto ser transformado e publicado em livro ${ }^{20}$.

O suporte livro, a nosso ver, propicia que os saberes dessa narrativa ganhem empregabilidade pedagógica em diversas práticas de letramentos críticos em variados contextos político-pedagógicos ao redor do mundo. Além disso, tal movimento indicia, mais uma vez, um gesto político decolonial de visibilização de uma discursividade que sofreu um longo processo de apagamento, mas permaneceu viva no âmbito da cultura oral e, nas últimas décadas, vem ganhando mais potencial de impacto e circulação, devido a sua reapropriação e tradução intercultural por meio da autoria do Subcomandante Marcos e do agenciamento dos promotores de educação engajados no movimento zapatista. Nesse sentido, a literatura ao estabelecer diálogo entre os sujeitos configura-se, na nossa opinião, como uma "interação inesgotável" (TODOROV, 2009), mas não na clave de uma pseudouniversalidade que ignora as 
relações de tempo/espaço e os contextos culturais, e sim como um discurso atravessado por diferentes pedagogias, capaz de ensinar por meio da sensibilização intercultural e do contato com a alteridade, despertando assim o senso de criticidade nos seus possíveis leitores.

\section{Considerações finais}

Neste artigo, discutimos uma concepção discursiva de linguagem, refletindo sobre o modo como a ideologia engendra condições de possibilidade do dizer e de relações saber-poder - tradicionalmente assentadas sobre a matriz epistemológica eurocêntrica -, com vistas a demonstrar o valor crítico e a relevância pedagógica da performatividade decolonial exercida pela transposição à escrita literária, empreendida pelo Subcomandante Marcos, do EZLN, dos mitos e narrativas das comunidades ameríndias da região de Chiapas (México). Tal narrativa promove processos de desconstrução do paradigma colonial em direção a uma abertura às epistemologias do Sul (SANTOS, 2018), aberta aos saberes dos povos originários.

Levando em conta que os estudos discursivos dialogam, transdisciplinarmente, com diferentes linhas teóricas, mobilizamos uma articulação com a pedagogia decolonial, que reivindica "[...] um sentido prático e concreto em favor das lutas de descolonização, libertação e humanização" (WALSH, 2013, p. 42). Nesse sentido, tratamos de refletir sobre as estratégias pedagógicas decoloniais num campo expandido, pensando-as para além da realidade escolar em si, de modo a focalizar o atravessamento de uma concepção pedagógica decolonial no âmbito do discurso literário zapatista - concepção esta debatida por meio da análise do comunicado intitulado La historia de los colores, assinado pelo Subcomandante Marcos.

Na leitura que empreendemos de La historia de los colores, identificamos a presença de uma construção narrativa ficcional atravessada por uma dimensão pedagógica, uma vez que resgata saberes da tradição oral indígena, transpondo-os para a escrita, o que permite sua utilização em diferentes processos de letramentos críticos e de revisão dos cânones de extração colonial, apontando assim uma interessante estratégica de correlação entre educação e literaturas indígenas. 
Acreditamos que esta pesquisa pode contribuir para o avanço de perspectivas transdisciplinares que partam da articulação entre estudos de linguagem, literatura e educação. O EZLN configura-se, a nosso ver, como um instigante movimento contra-hegemônico da esquerda latino-americana por fazer o político transitar diversas esferas do discurso, associando de maneira potente, conforme demonstramos, a enunciação literária a uma inflexão pedagógica decolonial, utilizando a linguagem como um vetor fundamental no processo de construção e convencimento de suas demandas, lutando, em especial, pela criação de novas formas de ver, pensar e (re)experienciar a cultura e a educação popular.

\section{REFERÊNCIAS}

ALTHUSSER, Louis. Ideologia e aparelhos ideológicos do Estado. Lisboa: Presença, 1970.

ARELLANO, Alejandro; OLIVEIRA, Ariovaldo (org.). Chiapas: construindo a esperança. São Paulo: Paz e Terra, 2002.

BAKHTIN, Mikhail. Estética da criação verbal. Trad. Paulo Bezerra. São Paulo: Martins Fontes, 2003.

BARONNET, Bruno. Autonomía y educación en Chiapas: prácticas políticas y pedagógicas en los pueblos zapatistas. In: WALSH, Catherine (org.). Pedagogías decoloniales: prácticas insurgentes de resistir, (re)existir y (re)vivir (Tomo I). Quito: Abya-Yala, 2013, p. 305-329.

BENJAMIN, W. O narrador. In: BENJAMIN, Walter. Magia e Técnica, arte e política: ensaios sobre literatura e história da cultura. Trad. Sérgio Paula Rouanet. São Paulo: Brasiliense, 1987. 
EZLN. La historia de los colores. Comunicado de 27 de outubro de 1994. Disponível em: https://enlacezapatista.ezln.org. mx/1994/10/27/la-historia-de-los-colores/. Acesso em: $10 \mathrm{fev}$. 2021.

ESTRADA SAAVEDRA, Marco. ¿Autonomía o hegemonía? Un análisis de la junta de buen gobierno hacia la Esperanza en las Cañadas tojolabales de la Selva Lacandona. El Cotidiano, vol. 21, núm. 137, Universidad Autónoma Metropolitana, Unidad Azcapotzalco, Distrito Federal, México, mayo-junio, p. 52-61, 2006.

FOUCAULT, Michel. História da sexualidade: a vontade de saber. Trad. Maria Thereza da Costa Albuquerque e Guilhon Albuquerque. Rio de Janeiro: Edições Graal, 1988.

FREIRE, Paulo. Pedagogia do oprimido. Rio de Janeiro: Paz e Terra, 1987.

GINZBURG, Carlo. O queijo e os vermes. Trad. Maria Betânia Amoroso. São Paulo: Companhia das Letras, 2006.

GOTLIB, Nádia Batella. Teoria do conto. São Paulo: Ática, 1995.

MAINGUENEAU, Dominique. Discurso literário. Trad. Adail Sobral. São Paulo: Contexto, 2006.

MARCOS, Subcomandante. La historia de los colores /The Story of Colors: A Bilingual Folktale from the Jungles of Chiapas. Illustrated by Domitila Domínguez. Translated by Anne Bar Din. El Paso, Texas: Editorial Cinco Puntos Press, 1999.

MARCOS, Subcomandante. A história das cores. Ilustração: Domitila Domínguez. Trad. Marcelo Barbão. São Paulo: Conrad, 2003.

MARCOS, Subcomandante. Nuestra arma es nuestra palabra: escritos selectos. Nueva York: Siete Cuentos Editorial, 2001.

MARTÍN-BARBERO, Jesús. Dos meios às mediações: comunicação, cultura e hegemonia. Trad. Ronald Polito e Sérgio Alcides. Rio de Janeiro: Editora UFRJ, 2003. 
MARX, Karl. O 18 brumário de Luís Bonaparte. Trad. Sílvio Donizete Chagas. São Paulo: Centauro, 2003.

MIGNOLO, Walter. La revolución teórica del Zapatismo: sus consecuencias históricas, éticas y políticas. Orbis Tertius, 1 (5), p. 63-81, 1997.

MIGNOLO, Walter. A colonialidade de cabo a rabo: o hemisfério ocidental no horizonte conceitual da modernidade. In: LANDER, E. (org.). A colonialidade do saber: eurocentrismo e ciências sociais - perspectivas latino-americanas. Buenos Aires: Clacso, 2005, p. 33-49.

MUÑOZ RAMÍREZ, Gloria. EZLN: 20 y 10, el fuego y la palabra. México, DF: La Jornada Ediciones, 2003.

NERUDA, Pablo. Confieso que he vivido. Barcelona: Seix Barral, 1974.

OLIVEIRA, Luiz Fernandes de; CANDAU, Vera. Pedagogia decolonial e educação antirracista e intercultural no Brasil. Educação em Revista, vol. 26, n.1 Belo Horizonte, p. 15-40, Abr. 2010. Disponível: <https://www.scielo.br/pdf/edur/v26n1/02. pdf>. Acesso em: 15/01/2021.

ORLANDI, Eni. Discurso e Leitura. $6^{\text {a }}$ ed. Campinas/SP: Cortez, 2001.

ORLANDI, Eni. A análise de discurso e seus entre-meios: notas a sua história no Brasil. Cadernos de Estudos Linguísticos, Campinas, 42, p. 21-40, jan./jun. 2002. Disponível em: https://periodicos.sbu.unicamp.br/ojs/index.php/cel/article/ view/8637139/4861. Acesso em: 15/01/2021.

ORTIZ, Pedro H. Falco. Zapatistas on-line: uma análise sobre o EZLN e o conflito em Chiapas, sua presença na internet e a cobertura da imprensa mexicana, argentina e brasileira. Dissertação de Mestrado (Prolam-USP), São Paulo, 1997.

SANTOS, Boaventura de Sousa. Construindo as epistemologias do Sul: para um pensamento alternativo de alternativas [Vol. 1]. Buenos Aires: CLACSO, 2018. 
TODOROV, Tzvetan. A literatura em perigo. Trad. Caio Meira. Rio de Janeiro: DIFEL, 2009.

WALSH, Catherine. Interculturalidad crítica y educación intercultural. In: Seminario Interculturalidad y Educación Intercultural, Instituto Internacional de Integración del Convenio Andrés Bello, La Paz, 2009, p. 1-18.

WALSH, Catherine. Pedagogías decoloniales: prácticas insurgentes de resistir, (re)existir y (re)vivir [Tomo I]. Quito: Abya-Yala, 2013.

\section{ABSTRACT \\ Colors and pedagogies of zapatista discourse}

In this article, we reflect on the decolonial pedagogical inflection of the Zapatista discourse, in order to discuss the simultaneously political and educational role which the appropriation of a literary narrative in this militant context indicates. Therefore, we analyze the announcement of the Zapatista Army of National Liberation - a Mexican indigenous resistance movement - entitled The Story of Colors (La historia de los colores) (EZLN, 1994), written by Subcomandante Marcos. For the development of the theoretical-analytical framework of this research, we articulate, in a transdisciplinary way, certain perspectives on discourse studies (ORLANDI, 2001; FOUCAULT, 1988), the inquiries from the social sciences regarding the epistemologies of the South (SANTOS, 2018), and the debate related to the decolonial pedagogy (WALSH, 2013; OLIVEIRA; CANDAU, 2010).

Keywords: Discourse; Decolonial Pedagogy; Literature; Epistemologies of the South; Zapatista Movement. 
Antonio Andrade é professor associado da Universidade Federal do Rio de Janeiro (UFRJ); docente permanente do Programa de Pós-graduação em Letras Neolatinas (PPGLEN); Bolsista de Produtividade em Pesquisa do CNPq. Possui licenciatura em Letras Português-Espanhol, mestrado e doutorado em Letras pela Universidade Federal Fluminense (UFF). Realizou pós-doutorado na Universität Potsdam (Alemanha). Lidera o grupo de pesquisa "Discursos, Práticas e Políticas de Ensino de Línguas e Literaturas - DIPPELL" (DGPCNPq). Possui vários artigos publicados e é coautor dos livros Translinguismo e poéticas do contemporâneo (7Letras, 2019), Indicionário do contemporâneo (Ed. UFMG, 2018) e Caminhos do hispanismo: vozes críticas, tendências teóricas (7Letras, 2015).

Patricia Fernandes é professora de espanhol da Secretaria Municipal de Educação (SMERJ), participa do grupo de elaboradores de material didático de espanhol (Material Rioeduca) para a SME-RJ, doutoranda do Programa de Pós-graduação em Letras Neolatinas (PPGLEN) e participa do grupo de pesquisa "Discursos, Práticas e Políticas de Ensino de Línguas e Literaturas - DIPPELL" (DGP-CNPq) liderado pelo Professor Doutor Antonio Andrade . 